\title{
ПРОБЛЕМЫ ГАРМОНИЗАЦИИ И УНИФИКАЦИИ ДЕФИНИЦИЙ «ТВОРЧЕСТВО», «ТВОРЧЕСКИЙ ТРУД» И «УМСТВЕННЫЙ ТРУД» В НАУКЕ И ЗАКОНОДАТЕЛЬСТВЕ СТРАН ЕАЭС
}

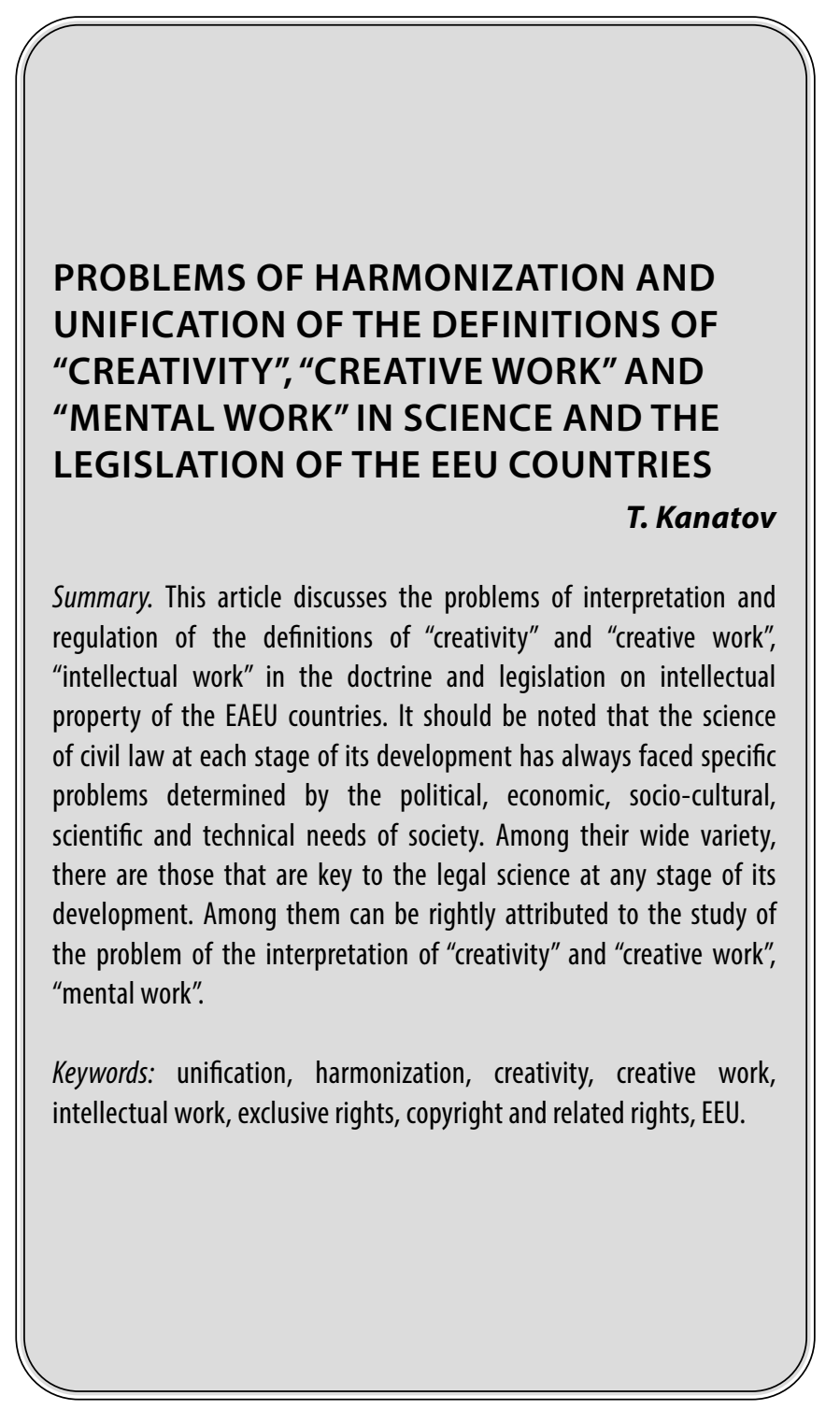

Д ефиниции «творчество», «творческий труд» и «умственный труд» до сих пор принадлежат к числу неоднозначных правовых категорий, что вносит неопределенность в толкование базовых конструкций суперинститута интеллектуальной собственности, создавая немало проблем в правоприменительной практике стран ЕАЭС. В целях гармонизации и унификации терминологии необходимо проанализировать подходы к определению этих понятий в науке и законодательстве стран ЕАЭС.
Канатов Танат Канатович

Доктор права, ассочиированный профессор, Московский государственный университет имени М.В. Ломоносова natan82008@mail.ru

Аннотация. В данной статье рассматриваются проблемы трактовки и регламентации дефиниций «творчество» и «творческий труд», «умственный труд» в доктрине и законодательстве об интеллектуальной собственности стран ЕАЭС. Следует отметить, о том, что перед наукой гражданского права на каждом этапе ее развития всегда стояли конкретные проблемы, определяемые политическими, экономическими, социально-культурными и научно-техническими потребностями общества. Среди их большого разнообразия существуют такие, которые являются ключевыми для юридической науки на любом этапе ее развития. К их числу можно с полным основанием отнести исследование проблемы трактовки «творчество» и «творческий труд», «умственный труд».

Ключевые слова: унификация, гармонизация, творчество, творческий труд, умственный труд, исключительные права, авторские и смежные права, ЕАЭС.

Феномен творчества на протяжении длительного времени исследуется в системе различных наук, прежде всего в философии, социологии, психологии, литературоведении, искусствоведении, других науках, в том числе в экономике и праве. Однако до настоящего времени сколько-нибудь приемлемого толкования творчества учеными не предложено.

В труде «О неправомерности переиздания книг» (1785 г.) И. Кант одним из первых провел различие 
между книгой как произведением механическим, относя ее к области вещного права, и ее содержанием, которое он воспринимал как обращение автора к нации и на которое, по его мнению, распространяется личное право.

Концепция авторского права, хотя и обрела оформление в международном соглашении - Бернской Конвенции 1886 г., понятий «творчество», «творческий труд» и «умственный труд» тоже не раскрывает, а лишь закрепляет определение «литературные и художественные произведения», которое «охватывает любую продукцию в области литературы, науки и искусства, вне зависимости от способа и формы ее выражения» [1].

Изменения представлений о творчестве, вызванные бифуркациями в обществе и хозяйственной жизни в XX-XXI веках оказали огромное влияние на представления о творчестве, творческом и умственном труде, что нашло отражение не только в законодательстве стран ЕАЭС и судебной практике [2], но и научных исследованиях.

Рассматривая категории «творчество», «творческий труд» и «умственный труд», нельзя обойти вниманием взгляды русских цивилистов на природу творчества. Так, профессор И.Г. Табашников в труде «Литературная, музыкальная и художественная собственность с точки зрения науки гражданского права и постановлений законодательств...» (1878) обозначил творческие произведения как «произведения ума», т.е. продуктов интеллектуального труда. К.Н. Победоносцев обозначил двойственность в понимании творческого произведения, которое есть «нечто исшедшее от него» (от автора), «им порожденное, получившее от него бытие ... произведение духа и мысли, выраженное в слове, принадлежит, прежде всего, самому автору не как телесная вещь, но как откровение и выражение его личности и духа, в нем обитающего» [3, 767c.]. Для Я.А. Канторовича авторское произведение - это не «духовное творчество», а «умственное», «не деятельность духа, а продукт этой деятельности, который со своей стороны предназначен к воздействию на человеческий дух» [4, С. 110]. Г.Ф. Шершеневич понимал объект авторского права как «продукт духовного творчества, облаченный в определенную форму и предназначенный к обращению в обществе» [5, C. 414].

Профессор Ю.С. Гамбаров был одним из тех, кто попытался выделить признаки результатов интеллектуальной деятельности: 1) бестелесная природа и неразрывная связь с личностью; 2) фиктивный характер; 3) имущественная ценность; 4) относительная независимость (самостоятельность) в отношении к телесным вещам; 5) абсолютная защита прав на такие объекты [6, 793с.].
Несмотря на широту взглядов, высказанных цивилистами в конце XIX и начале XX вB., многолетние научные баталии мало продвинули исследователей в постижении творчества в правовой науке. Своеобразную черту в этих спорах подвел А.А. Пиленко, который еще в начале $X X$ века признал «наивным искать объективные мерки для понятия творчества» [7, С. 236].

Тем не менее, в прошлом веке сразу несколько известных теоретиков гражданского права высказали свои представления о творчестве. Так, В.И. Серебровский охарактеризовал произведение как совокупность «идей, мыслей и образов, получивших в результате творческой деятельности автора свое выражение в доступной для восприятия человеческими чувствами конкретной форме, допускающей возможность воспроизведения» [8, C. 32].

М.В.Гордон полагал, что произведение возникает как результат творческой деятельности определенного автора, подчеркивая субъективную сторону - процесс создания произведения есть условие признания авторства. Объект авторского права «может быть характеризован только как результат творчества, а не как простой предмет материального мира» [9, С. 10].

Б.С. Антимонов и Е.А. Флейшиц обозначили субъектом авторского права «лицо, своим творческим трудом создавшее произведение науки, литературы или искусства» $[10$, С. 65].

О.С. Иоффе считал творчество «интеллектуальной деятельностью, завершающейся производящим актом, в результате которого появляются новые понятия, образы и (или) формы их воплощения, представляющие собой идеальное отражение объективной действительности» $[11$, С. 5].

И.Я.Ионас, рассматривая проблему творчества не только теоретически, но и практически, писал в 1963 г.: «Не учитывая критерия творчества, судья или эксперт не будут в состоянии решать чисто практические вопросы и споры, возникающие в связи с созданием произведений науки, литературы, искусства...» [12, С. 12]. «Правовым критерием для отграничения авторской деятельности от смежных видов интеллектуальной работы» И.Я.Ионас предлагает считать «аналитико-синтетический характер умственной деятельности, имеющий своим результатом создание новых идей, образов, понятий, суждений, силлогизмов или новой комбинации известных идей, образов, понятий» $[12$, С. 20]. Позднее И.Я. Ионас пришел к выводу, что понятие произведения шире понятия произведения творчества [13, С. 10]. Под произведением ученый понимал результат мыслительной (или интеллектуальной) деятельности человека [13, С. 9]. 
Несмотря на то, что советские правоведы, достаточно глубоко изучили зарубежную теорию и практику патентного права [14, 340с.], выделить какую-либо четкую правовую взаимосвязь изобретательства с творчеством из исследований того периода затруднительно. Как исключение можно рассматривать исследование К.Н. Наменгенова, где он, подчеркивая важность творческого отношения к труду в связи с развитием массового технического творчества, считал, что Конституция СССР создает «широкий простор для проявления творческих способностей советских людей, гарантирует свободу технического творчества, провозглашает охрану прав изобретателей и рационализаторов» [15, C. 2].

В отдельных научных работах творческий труд сопряжен с постоянной необходимостью преодолевать устоявшиеся в той или иной области представления и стереотипы, нацелен на поиск принципиально новых научных, технологических и организационных решений. Антиподом творческого труда выступает шаблонный труд, который характерен для низовых, наиболее простых по квалификационному уровню ячеек в системе общественного труда [16, 80с.]. Т.е. признаком творчества при таком подходе предлагается прогрессивность как преодоление сложившихся стереотипов.

Есть мнение, что понятие интеллектуального труда отличается от понятия умственного труда по целому ряду признаков. «Интеллектуальный труд в большей степени персонифицирован как труд более высокого качества и социальной эффективности. Он в большей степени, чем умственный труд, монополизирован определенной группой людей». Речь идет, прежде всего, о представителях творческих профессий и ученых. «По своему характеру и содержанию интеллектуальный труд является информационно емким и производительным. Средством интеллектуального труда являются интеллектуальные и коммуникационные возможности человека и общества» [17, С. 108-111].

С конца XX века творчество начинает рассматриваться главным образом с интеллектуалистических позиций, как создание «нечто нового» [18, С. 83]. С развитием техники и новых технологий все более распространенным стало понимание творческого и умственного труда через инновации (англ. innovation - нововведение) - создание, распространение и внедрение новшества.

Однако, до настоящего времени самым очевидным пробелом гражданского права ЕАЭС продолжает оставаться отсутствие в законодательстве не только дефиниций творчества и творческого труда, но и понятия умственного (интеллектуального) труда, а также понятия «результат интеллектуальной деятельности». В соответ- ствии со ст. 1257 ГК РФ, «автором произведения науки, литературы или искусства признается гражданин, творческим трудом которого оно создано». Это положение дополнительно разъяснено в ст. 1228 ГК РФ: «Не признаются авторами результата интеллектуальной деятельности граждане, не внесшие личного творческого вклада в создание такого результата».

В правовой науке концепты «творчество», «творческий труд» и «умственный труд» рассматриваются весьма вариативно и во многом отличаются от представлений русских и советских цивилистов. Приведем лишь несколько из определений и суждений по этой проблематике.

Э.П. Гаврилов понимает творчество как «деятельность человека, порождающую нечто качественно новое и отличающееся неповторимостью, оригинальностью и уникальностью» [18, С. 83].

А.П. Сергеев: «До тех пор, пока мысли и образы автора, существуют лишь в виде творческого замысла, они не могут быть восприняты другими людьми, и, следовательно, не существует и практической надобности в их правовой охране» [19, С. 111-112].

Т.Г. Макаров: «... под творческой деятельностью понимается процесс создания чего-то качественно нового, а ее результат определяется как итоговый продукт... Право начинает действовать тогда, когда автор вступает в общественные отношения по созданию и использованию результатов своей творческой деятельности» [20, С. 302-308].

Но вряд ли корректна позиция В.А. Дозорцева, который предложил разделять результаты творческого и интеллектуального труда. Как заметил И.А. Зенин, «по нормам русского языка интеллект напрямую трактуется как ум, разум и как источник умственного, а значит, творческого труда» [21, С. 259].

Если обратиться к зарубежным исследованиям поэтой проблеме, то европейская правовая наука, занимающаяся вопросами творческого труда, еще не в полной мере избавилась от влияния личностно-ориентированных доктрин XVIII-XIX вв. Одним из представителей «личностного» подхода в праве был германский юрист, профессор Отто фон Гирке, отстаивающий целесообразность субъективной интерпретации критерия творчества. При такой логике охраноспособными могут признаваться только произведения, отражающие исключительно личность автора (его особый стиль, манеру письма).

В противовес субъективному, объективный подход предполагает сравнение произведения с уже существу- 
ющими. Личностная (субъективная) ориентированность авторского права ограничена, при попытке применения только субъективных критериев к произведению, установить его принадлежность к автору возможно далеко не всегда. Тем не менее, концепция «интеллектуального творчества автора» впервые появилась в европейской Директиве 91/250/ЕЕС от 14 мая 1991 г. о правовой защите компьютерных программ.

Но ни европейское, ни международное право не дают ответов на вопросы, что такое творчество, творческий труд, умственный труд. В международном праве нормы о труде, праве на труд, трудовых отношениях и защите трудовых прав относятся к области трудового права и слабо коррелируют с положениями права интеллектуальной собственности.

Сопоставление действующих норм законодательства стран ЕАЭС показывает, что «творческий труд» (или «творческая деятельность») как условие признания лица, создавшего произведение присутствует в законодательстве всех стран Союза.

ГК РБ не использует термин «автор», заменяя его словом «патентообладатель». Нормы ГК РК о правах промышленной собственности отсылают к Патентному закону РК от 16 июля 1999 г. № 427 [22], нормы ГК РА к Закону РА «Об изобретениях, полезных моделях и промышленных образцах» от 28 июня 2008 г. № 3Р-111 [23], а нормы ГК РБ - к Закону РБ «О патентах на изобретения, полезные модели, промышленные образцы» от 16 декабря 2002 г. № 160-3 [24].

Ключевой вывод, который вытекает из анализа норм гражданских кодексов стран ЕАЭС, содержащих термин «творческий труд», это отсутствие его легального толкования, вокруг данного понятия образовался вакуум.

Обращает на себя внимание тот факт, что в Обзоре судебной практики по делам, связанным с разрешением споров о защите интеллектуальных прав от 23.09.2015 г., судам рекомендовано учитывать, что по смыслу статей 1228, 1257, 1259 ГК РФ в их взаимосвязи, результатом интеллектуальной деятельности является только результат, созданный творческим трудом. Однако, никаких критериев творческого труда в Обзоре не приводится. Таким образом, ни в законодательстве, ни в правовой науке, никакой ясности относительно категории «творческий труд» нет.

На данный момент в большинстве правовых актов стран ЕАЭС происходит лишь констатация права на творчество и свободу творчества. Один из таких нормативных подходов закреплен, к примеру, в российском законе «О науке и государственной научно-техни- ческой политике», где субъектам научной и (или) научно-технической деятельности гарантируется свобода творчества, защита от недобросовестной конкуренции, а также предоставляется право выбора направлений и методов проведения научных исследований и экспериментальных разработок (ст. 3) [25]. Но едва ли «свободу творчества» можно рассматривать как обязательный признак творчества, а тем более как критерий умственного труда.

И.А. Зенин, один из немногих российских ученых-правоведов, глубоко изучающих проблемы творчества и творческого труда, наблюдая за процессом познания творчества и анализируя нормы действующего законодательства, пришел к выводу, что в юридическом смысле творческим трудом следует считать любой умственный труд, а его результат - объектом авторского права, кроме случаев, когда:

\section{1) установлен плагиат;}

Признать творческим умственный труд плагиатора нельзя. Плагиатом признается использование произведения без цитирования [26, С. 33-35]. Эта проблема лишь сравнительно недавно стала объектом пристального внимания со стороны экспертного и научного сообщества стран ЕАЭС. К исследованию понятия «плагиат» обращались многие ученые, среди которых В.А. Белов, С.А. Денисов, И.А. Зенин, Р.А. Мерзликина, И.В. Овчинников и другие. Сущность плагиата состоит в умышленном присвоении авторства, т.е. нарушитель осознает, что выдает чужой результат интеллектуального труда (или его фрагмент) за свой собственный [27, С. 272].

В правоприменительной практике впервые проблему плагиата обозначил Пленум ВС РФ от 26.04.2007 № 14 [28], в Постановлении которого разъяснено, что присвоение авторства может заключаться в объявлении себя автором чужого произведения, выпуске чужого произведения (в полном объеме или частично) под своим именем, издании под своим именем произведения, созданного в соавторстве с другими лицами, без указания их имени;

2) результат признан объектом патентных и других подобных прав;

3) на результат установлен режим коммерческой тайны и он является объектом фактической монополии, то есть ноу-хау;

4) этот результат (герб, флаг, клон и т.п.);

5) умственный труд признан по закону оказанием автору результата технического, материального и т.п. содействия либо помощи (п. 1 ст. 1228 ГК РФ); 
6) умственный труд был направлен только на создание вещи как объекта вещных прав [29].

С точки зрения И.А. Зенина, которую следует поддержать, результатами умственного труда по смыслу п. 1 ст. 1225 ГК РФ можно считать только результаты, соответствующие двум основным условиям:

1. их охрана должна предусматриваться законом;

2. охрана должна предоставляться конкретному результату интеллектуальной деятельности или средству индивидуализации [30, С. 14].

Новый импульс дискуссия о природе умственного (интеллектуального) труда получила в связи с цифровизацией различных сфер человеческой деятельности. В самом общем смысле «цифровизация» (от англ. digitalization) - это преобразование информации в цифровую форму, процесс переноса деятельности человека и продуктов этой деятельности в цифровую среду. В рамках индустрии «Промышленность 4.0» ключевым аспектом становится цифровое производство, его конкурентоспособность определятся уровнем цифровизации [31, С. 108-116].

Суть наступающей «эпохи сетевого интеллекта» состоит «не только в сетевых технологиях, но и во взаимодействии людей посредством сетевых технологий», которые «объединяют интеллект, знания и творчество для совершения прорыва в создании общественного капитала и благополучия» [32, С. 143].

В соответствии с цифровой трансформацией экономики стала развиваться новая отрасль права - цифровое право, появился новый объект гражданских прав цифровые права. С 1 октября 2019 г. [33] ст. 128 ГК РФ звучит следующим образом: «К объектам гражданских прав относятся вещи (включая наличные деньги и документарные ценные бумаги), иное имущество, в том числе имущественные права (включая безналичные денежные средства, бездокументарные ценные бумаги, цифровые права); результаты работ и оказание услуг; охраняемые результаты интеллектуальной деятельности и приравненные к ним средства индивидуализации (интеллектуальная собственность); нематериальные блага».

Цифровыми правами российский закон признает «обязательственные и иные права, содержание и условия, осуществления которых определяются в соответствии с правилами информационной системы, отвечающей установленным законом признакам» (ст. 141.1 ГК РФ).

Нормативное определение информации, информационных технологий и смежных с ними категорий помещено в Федеральный закон от 27.07.2006 № 149 «Об информации, информационных технологиях и о за- щите информации» [34] (далее - «Закон № 149-ФЗ), где информация понимается как «сведения (сообщения, данные) независимо от формы их представления», а информационные технологии - как «процессы, методы поиска, сбора, хранения, обработки, предоставления, распространения информации и способы осуществления таких процессов и методов».

Но если понятие термина «информация» содержат специальные правовые акты всех стран ЕАЭС, то дефиниция «цифровые права» как объект гражданских прав получила закрепление только в ГК РФ.

Но не во всех странах ЕАЭС идея включения цифровых прав в гражданское законодательство находит поддержку в научном сообществе. Так, казахстанский ученый, доктор юридических наук М.К. Сулейменов высказывает большие опасения, и даже осуждение принятия поправок в ГК РФ: «...не надо торопиться вносить изменения в ГК и другие законы. Все эти проблемы, связанные с наступлением эры компьютеризации, роботизации и цифровизации, являются настолько непроработанными с точки зрения гражданского права, что включение их в законодательство может привести к непредвиденным последствиям. У меня большие сомнения по вопросу о необходимости включения в настоящий период понятия цифровых прав в ГК» [35].

Невозможно отрицать, что новые реалии в рамках цифровой трансформации поставили перед правовой наукой величайшую познавательную проблему - регламентировать воздействие цифровизации на экономическую жизнь и торговый оборот новых объектов ИС, выразить этот научно-технологический феномен в правовых категориях. Всевозможные подходы к регламентации информации уже не справляются с этой задачей, необходимо примирить имеющуюся доктрину интеллектуальной собственности с реальностью интеллектуального производства, включив умственный (интеллектуальный) труд и новые объекты ИС в систему общественных отношений.

Проникновение глобальной цифровой парадигмы в экономику и правовые системы, неизбежно будет детерминировать стремление стран к гармонизации и унификации законодательства. В частности, в Европе, как уже отмечалось выше, происходит процесс унификации и гармонизации, исключительных прав стран-членов ЕС в виде снятия барьеров, активизации коммерческого оборота и создания единого цифрового рынка. И страны ЕАЭС не могут оставаться в стороне от этих процессов, каким бы сложным не казался им этот путь.

Следует признать, что многочисленные попытки в познании творчества, творческого труда и умствен- 
ного труда в правовой науке особым успехом не увенчались, главное противоречие исследователями разрешено не было, поскольку творчество имманентно, оно присуще практически любому виду человеческой деятельности. В настоящее время эти категории проходят очередную трансформацию, их содержание меняется.

Окончательная точка в дискуссии о природе творчества, творческого и интеллектуального труда в рамках суперинститута интеллектуальной собственности не скоро будет поставлена. Следует выразить солидарность с теми авторами, которые считают, что проблема определения критериев творчества в значительной мере обусловлена тем обстоятельством, что до сих пор в науке господствует традиционное определение труда [36, С. 133-137].

Из всего сказанного следует, что законодательство стран ЕАЭС должно содержать легальное юридическое определение творческого труда и правовые критерии его результата.

\section{ЛИТЕРАТУРА}

1. Бернская Конвенция по охране литературных и художественных произведений от 09.09.1886 (ред. от 28.09.1979).

2. Обзор судебной практики по делам, связанным с разрешением споров о защите интеллектуальных прав (утв. Президиумом Верховного Суда РФ 23.09.2015) // Бюллетень Верховного Суда РФ.— 2015.— № 11, ноябрь.

3. Победоносцев К.П. Курс гражданского права: Вотчинные права. Ч. 1. / К.П. Победоносцев. — С.-Пб.: Синод. тип., 1896. — 767 с.

4. Канторович Я.А. Авторское право на литературные, музыкальные, художественные и фотографические произведения. Систематический комментарий к закону 20-го марта 1911 г.— 2-е изд., доп. / Я.А. Канторович. — Петроград: Тип. АО б. «Брокгауз-Ефрон», 1916. С. 110.

5. Шершеневич Г.Ф. Учебник русского гражданского права, С. 414.

6. См.: Гамбаров Ю.С. Курс гражданского права: Часть общая. Т. 1 / Ю.С. Гамбаров. — С.-Пб.: Тип. М.М. Стасюлевича, 1911. 793 С.

7. Пиленко А.А. Право изобретателя / Ред. кол. тома: В.С. Ем, Т.В. Мальчикова; Вступит. ст. И.А. Зенина; Биограф. очерк В.С. Ема, Д.А. Ларионова / А.А. Пиленко.— М.: Статут, 2001. С. 236.

8. Серебровский В.И. Вопросы советского авторского права / В.И. Серебровский. - М.: Изд-во АН СССР, 1956. С. 32.

9. Цит. по: Ионас В.Я. Критерий творчества в авторском праве и судебной практике / Ионас В.Я.— М.: Юрид. лит., 1963. С. 10.

10. Антимонов Б.С. Авторское право / Б.С. Антимонов, Е.А. Флейшиц. - М.: Госюриздат, 1957. С. 65.

11. Иоффе 0.С. Советское гражданское право: Курс лекций: в 3 ч. / 0.С. Иоффе. — Л.: Изд-во Ленингр. ун-та, 1965. - Ч. 3. С. 5.

12. Ионас В.Я. Критерий творчества в авторском праве и судебной практике / В.Я. Ионас. - М.: Юрид. лит., 1963. - 138 стр.

13. Ионас В.Я. Произведения творчества в гражданском праве / Ионас В.Я. — М.: Юрид. лит., 1972. — 168 стр.

14. Матвеев Г.А. Патентное право и западноевропейская интеграция капиталистических стран: автореф. дис. ... канд. юрид. наук / Г.А. Матвеев.М., 1968. 26 с.; Патентное законодательство капиталистических стран / Пер.: Дозорцева В.А., Мальцман Т.Б., Рубанова А.А.; Под ред. и со вступ. ст.: Е.А. Флейшиц.- М.: Иностр. лит., 1959. 340 с.

15. Наменгенов К.Н. Абсолютные и относительные изобретательские правоотношения: автореф. дис. д-ра юрид. наук: 12.00.03 / К.Н. Наменгенов.— М., 1982. C. 2.

16. Бушмарин И.С. Трудовые ресурсы творческого типа — основа эволюции и экономики общества / И.С. Бушмарин. 一 М.: ЭПИцентр, 2002.80 с.

17. Лебединцева Л.А. Понятие и сущность интеллектуального труда в современных экономико-социологических исследованиях / Л.А. Лебединцева // 0бщество. Среда. Развитие (Terra Humana). — 2012. — № 1.— С. 108-111.

18. Гаврилов Э.П. Советское авторское право. Основные положения и тенденции развития. — Наука, 1984. — 222 стр.

19. Сергеев А.П. Право интеллектуальной собственности в Российской Федерации. - М.: Проспект, 2000. С. 111-112.

20. Макаров Т.Г. Понятие творчества в психологии и юриспруденции / Т.Г. Макаров // Ученые записки Казанского университета. Серия «Гуманитарные науки».—2018. - Том 160.—Кн. 2.—С. 302-308.

21. Зенин И.А. Творческий труд как правовая категория / И.А. Зенин // Гражданское право: современные проблемы науки, законодательства, практики. Сборник статей к юбилею Е.А. Суханова. - М.: Статут, 2018. С. 259.

22. Патентный закон Республики Казахстан от 16 июля 1999 г. № 427 (ред. 28.10.2019) // Ведомости Парламента РК. 1999. № 20. Ст. 718; 2004. № 17. Ст. 100.

23. Закон Республики Армения «0б изобретениях, полезных моделях и промышленных образцах» от 28 июня 2008 г. № 3Р-111 (ред. от 18.10.2016) // Официальные ведомости РА. 2008. № 42 (632). Ст. 715.

24. Закон Республики Беларусь «0 патентах на изобретения, полезные модели, промышленные образцы» от 16 декабря 2002 г. № $160-3$ (ред. от 18.12.2017) // Национальный реестр правовых актов РБ. — 03.01.2003.— № 1. — 2/909.

25. Федеральный закон от 23 авг. 1996 № 127-Ф3 «0 науке и государственной научно-технической политике» (ред. от 26.07.2019) // Собрание законодательства РФ. 1996. № 35. Ст. 4137.

26. Богданова, О.В. Присвоение авторства как способ нарушения авторских прав / 0.В. Богданова // Право и экономика.— 2016. — № 8. — С. 33-35.

27. Мерзликина Р.А. Право интеллектуальной собственности: Учебник / Р.А. Мерзликина. 2-е изд., перераб. и доп. - М.: Финансы и статистика; Ставрополь: Сервисшкола, 2009. С. 272. 
28. Постановление Пленума Верховного Суда РФ от 26.04.2007 № 14 «0 практике рассмотрения судами уголовных дел 0 нарушении авторских, смежных, изобретательских и патентных прав, а также о незаконном использовании товарного знака» // СПС «Консультант Плюс».

29. Зенин И.А. Категории творчества, справедливости, морали и публичного порядка в российском праве интеллектуальной собственности: доклад на XI Международном форуме «Интеллектуальная собственность - XXI век».

30. Зенин И.А. Проблемы российского права интеллектуальной собственности (избранные труды) / И.А. Зенин.— М.: Статут, 2015. С. 14.

31. Истомина Е.А. Оценка трендов цифровизации в промышленности // Вестник Челябинского государственного университета. Экономические науки.—2018. - № 12 (422). — Вып. 63.— С. 108-116.

32. Бухт Р. Определение, концепция и измерение цифровой экономики / Р. Бухт, Р. Хикс // Вестник международных организаций. - 2018. - Т. 13.— № 2. C. - 143-172.

33. Федеральный закон от 18.03.2019 № 34-Ф3 «0 внесении изменений в части первую, вторую и статью 1124 части третьей Гражданского кодекса Российской Федерации» // Собрание законодательства РФ. 2019. № 12. Ст. 1224.

34. Федеральный закон от 27.07.2006 № 149-Ф3 (ред. от 02.12.2019) «06 информации, информационных технологиях и о защите информации» // Собрание законодательства РФ. 2006. № 31 (1 ч.). Ст. 3448.

35. Сулейменов М.К. Гражданское право Казахстана в современном мире: влияние на развитие национального права. [Электронный ресурс]. URL: https:// legalpro.kz/grazhdanskoe-pravo-kazakhstana-v-sovre/ (дата обращения 15.01.2020).

36. Новикова Н.А. К вопросу о необходимости переосмысления понятия «творческий труд» / Н.А. Новикова // В сборнике: Современное общество: наука, техника, образование материалы Всероссийской научной конференции с международным участием в 4-х томах. 2016. С. $133-137$.

(c) Канатов Танат Канатович ( natan82008@mail.ru).

Журнал «Современная наука: актуальные проблемы теории и практики»

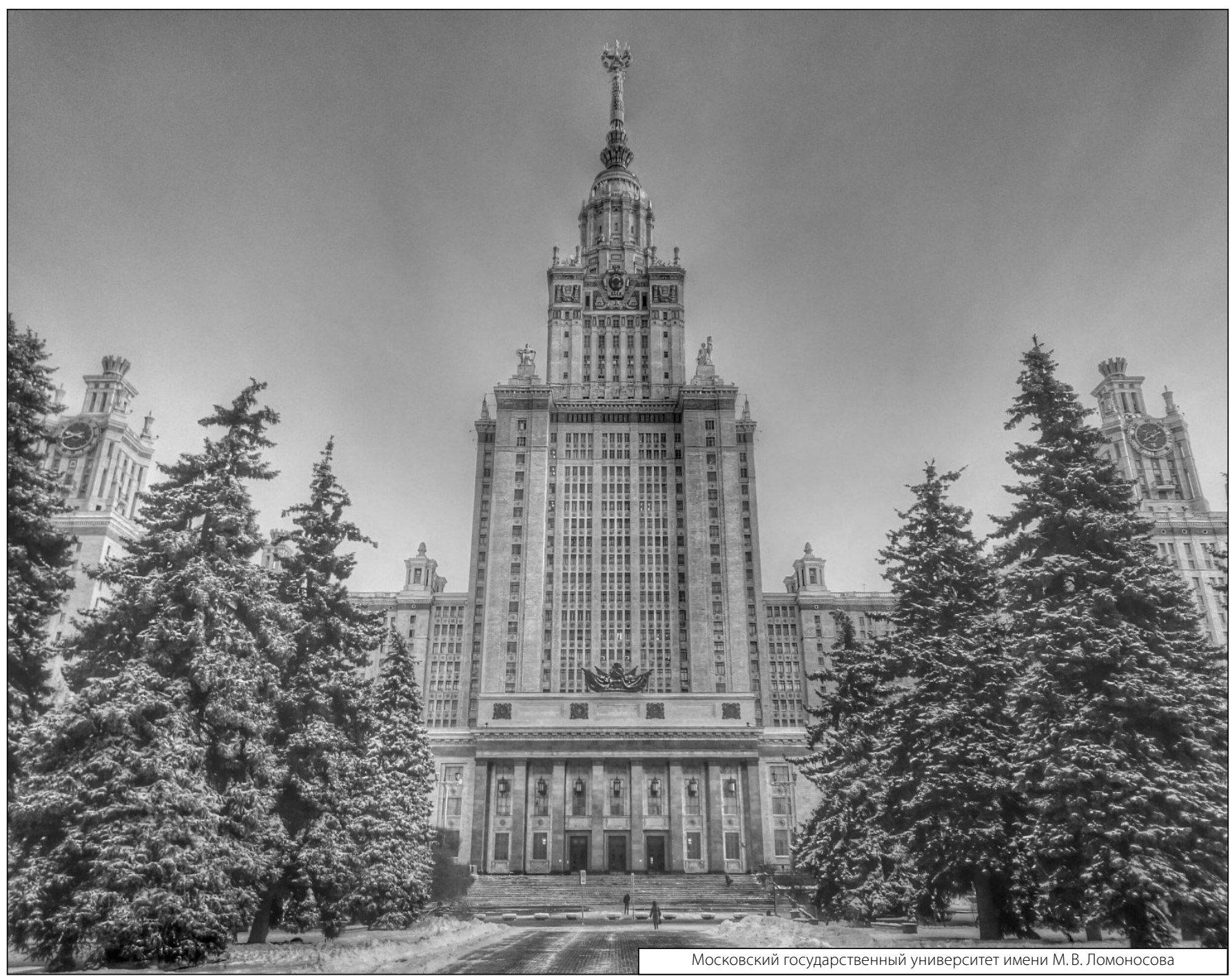

